\title{
Knowing How to Put Knowledge First in the Theory of Justification
}

\author{
Paul Silva Jr. \\ psilvajr@gmail.com
}

March 26, 2016

Keywords: justification, virtue epistemology, knowledge-first, know-how

\section{Introduction}

Traditional epistemology assumed that we could give an analysis of knowledge in terms of justification and other conditions. Knowledge-first epistemologists have turned that assumption on its head, demonstrating that a fair bit of epistemology can be done, and done well, without it. ${ }^{1}$ In the wake of this insight some have sought to bind justification to knowledge by offering accounts of justification in terms of knowledge. However, extant knowledge-first accounts of justification have failed to accommodate certain obvious facts about justification-something any plausible theory of justification should do. Indeed, even given the correctness of the knowledge-first approach, it would be an unsettling surprise if the vast majority of epistemologists were just systematically mistaken in their thinking about certain, seemingly fundamental facts about justification. For example, a one aim in this paper is to see whether an independently motivated knowledge-first approach to justification can respect certain core internalist intuitions about justification without running into other problems.

In what follows I provide a novel knowledge-first account of justification that avoids the pitfalls of existing accounts while preserving the underlying insight of knowledge-first epistemologies: that knowledge comes first. The view I propose is, roughly, this: justification is grounded in our practical knowledge (know-how) concerning the acquisition of propositional knowledge (knowledge-that). I first refine my thesis in response to immediate objections. In subsequent sections I explain the various ways in which this thesis is theoretically superior to existing knowledge-first accounts of justification. The upshot is a virtue-theoretic,

\footnotetext{
${ }^{1}$ Williamson (2000).
} 
knowledge-first view of justification that is internalist-friendly and able to explain more facts about justification than any other available view.

\section{The Initial View}

We are not simply retainers of propositional knowledge. We also know how to acquire it. You, for example, know how to figure out whether your bathroom faucet is currently leaking, you know how to figure out whether your favorite sports team won more games this season than last season, you know how to figure out the sum of 294 and 3342, and so on. In normal circumstances when you exercise such know-how you typically gain (and retain) propositional knowledge. If you know how to figure out whether the faucet is leaking and you use that know-how, the typical result will be knowledge that the faucet is leaking (if it is leaking) or knowledge that the faucet is not leaking (if it is not leaking). My thesis is that justification is crucially connected to this kind of know-how.

Here is one way of capturing the idea:

\section{Justification is Knowing How to Know That: Take 1}

(T1) S's belief that $\mathrm{P}$ is justified in circumstances C IFF (i) S knows how to know that $\mathrm{P}$ in $\mathrm{C}$, and (ii) S's believing that $\mathrm{P}$ is a result of her exercise of that know-how in $\mathrm{C}$.

The above account purports to explain the justification of beliefs in terms of propositional knowledge: a justified belief is what you get when you exercise your knowledge how to know that. $^{2}$

A few aspects of (T1) need clarification. Following Hawley (2003, 20-22), know-how is here relativized to "circumstances" by which I mean a thinker's potential environment and other relevant conditions that could obtain in a world. Take Greco's example of Jeter. ${ }^{3}$ He knows how to hit baseballs, but not in just any environment. War zones, hurricanes,

\footnotetext{
${ }^{2}$ I do not seek to explicate or analyze the notion of know-how being employed. In this way, the present account of justification is importantly neutral on the intellectualism/anti-intellectualism debate. If intellectualism is correct, justification may be in even greater debt to propositional knowledge than (T1) and its subsequent permutations indicate. But even if some form of anti-intellectualism is correct, we have here an account of justification that clearly puts propositional knowledge first. Would intellectualism make the account circular? Not necessarily. Bengson and Moffett's (2011) non-propositional intellectualism would not, nor would a form of propositional intellectualism that didn't reduce knowing how to know that $\mathrm{P}$ to knowing that $\mathrm{P}$.

${ }^{3}$ Greco $(2010,77 ; 2012,17 \mathrm{ff})$ offers an analysis of the circumstances relative to which Jeter has an ability to hit baseballs. But it's plausible that Jeter's ability to hit baseballs stems from his knowledge how to do so, and, as Hawley's (2003) discussion makes clear, much of what can be said about abilities can be said about know-how, especially when know-how's circumstantial parameter is made explicit. I pick this thread up again in discussion of Kelp's (forthcoming) knowledge first view.
} 
and sand storms are all environments relative to which Jeter does not know how to hit baseballs. Similarly, although Jeter knows how to hit base balls, he does not know how to hit baseballs under just any conditions. Jeter does not know how to hit baseballs with bats that weigh eight hundred pounds, or baseballs traveling at the speed of sound, or in the dark. The intuitive distinction between environments and conditions isn't crisp and permits overlap. Perhaps being in a place where intoxicating drugs are in the air counts as a condition, perhaps as an environment. Sorting out the relevant difference is unnecessary, and for present purposes I package them into know-how's circumstances. As Hawley points out, this relativization of know-how to circumstances is typically left implicit in our ordinary ascriptions of know-how. ${ }^{4}$

Second, concerning condition (i), I take it that $\mathrm{S}$ knows how to know that $P$ in $C$ only if the following conditions are met:

(i.a) There is a way of coming to know that $\mathrm{P}$ in $\mathrm{C}$.

(i.b) S knows how to exercise that way in C. ${ }^{5}$

(i.c) If $\mathrm{S}$ were in $\mathrm{C}$ and $\mathrm{S}$ were to exercise that way, $\mathrm{S}$ would succeed in knowing that $\mathrm{P}^{6}$

These conditions are not intended to identify what it is in virtue of that one possess knowledge how to know that $\mathrm{P}$ in $\mathrm{C}$. Rather, they are meant to highlight certain constitutive features involved in the target sort of know-how. Each of (i.a)-(i.c) involves reference to $a$ way of $\phi$-ing. Like most discussions of know-how, I offer no informative analysis of a way of $\phi$-ing. This is unproblematic for it's easy to think of so many perfectly commonplace examples that we can be confident that the notion is well-grounded. ${ }^{7}$

\footnotetext{
${ }^{4}$ To be clear, it's not the possession of know-how that is relativized to circumstances, but what it is that one know's how to do. One can possess knowledge how to light a match in normal circumstances even if one's actual circumstances are abnormal.

${ }^{5}$ To claim that one knows how to $\phi$ only if one knows how to exercise a way of $\phi$-ing may seem to generate a regress of some sort, but it doesn't. For it doesn't entail that knowing how to exercise a way of $\phi$-ing $W$ is a matter of knowing how to exercise a way, $\mathrm{W}^{*}$, of exercising $\mathrm{W}$. Plausibly, there are some ways of $\phi$-ing that are basic. This is closely connected to the observation that although we regularly follow rules only by following other rules, there are (and must be) some rules we follow directly, i.e. we follow them but not by following further rules. See Wedgwood (2002).

${ }^{6}$ Due to objections stemming from unlikely and random, failures to know in nearby worlds (cf. Pritchard, Millar, and Haddock $(2010,127))$ there is a case to made that this condition should read "would reliably succeed". Hawley $(2003,22-24)$ is sensitive to this general point, leaving it open that we should prefer a reliable counterfactual success condition rather than outright counterfactual success condition. (See also Stanley $(2011,127)$ and Williams (2008).) Although revising (i.c) to be a reliable success condition would help (T1) avoid the initial objection to follow, it would not help with the subsequent objections. Moreover, the views that succeed ( $\mathrm{T} 1$ ) will be able to handle the sorts of concerns that could be generated by permutations of the cases provided by Pritchard, Millar, and Haddock (2010, 127). So in the end it doesn't matter whether or not (i.c) is loosened to just a reliable success condition.

${ }^{7}$ For example, suppose you wish to distress a piece of furniture to increase its rugged aesthetic. There are
} 
The core idea behind (i.a) is that one cannot know how to $\phi$ in $\mathrm{C}$ unless it's possible to $\phi$ in some way in C. ${ }^{8}$ The core idea behind (i.b) is that knowing how to know that $\mathrm{P}$ in $\mathrm{C}$ is a matter of having a way of knowing that $\mathrm{P}$ which one knows how to exercise. When it comes to acquiring propositional knowledge apt examples will include our usual ways of responding to our perceptual, memorial, and introspective experiences to arrive at beliefs based on those experiences. ${ }^{9}$ The idea behind (i.c) is that exercising one's know-how in general must lead to success when one is in the right kind of circumstances. Without this kind of success condition it would just be counterintuitive to regard one as possessing the target sort of know-how. The importance of conditions (i.a)-(i.c) will become apparent below.

Third, condition (ii) captures the thought that if S's belief is to be justified, S's believing $\mathrm{P}$ has to result from S's exercise of her know-how to know that $\mathrm{P}$ in $\mathrm{C}$. It's not enough that one know-how to know that $\mathrm{P}$ in $\mathrm{C}$ and that one believe $\mathrm{P}$ in her actual circumstances. Rather, one's believing P must be brought about (and sustained) by one's knowledge how to know that $\mathrm{P}$.

Lastly, the relativization of know-how to circumstances cannot be overemphasized. Otherwise the present view would imply the problematic thesis that: a way of knowing $\mathrm{P}$ simpliciter can be a way of falsely believing $\mathrm{P}$ simpliciter. The view I'm advocating has no such implication for there is no such thing as a way of knowing $\mathrm{P}$ simpliciter. All ways of knowing propositions are circumstance-relative and only demand the "counterfactual success" indicated in (i.c) (Hawley (2003)). So what the present view is committed to is this: a way of knowing $\mathrm{P}$ in certain circumstances can be a way of falsely believing $\mathrm{P}$ in other circumstances. For this reason, merely exercising one's knowledge how to know that $\mathrm{P}$ in $\mathrm{C}$ doesn't entail that one knows $\mathrm{P}$ or that one is in C. In this sense, exercising know-how is non-factive. Moreover, it is crucial to emphasize that this relativization does not give way to the idea that someone can exercise her knowledge how to know that $\mathrm{P}$ in $\mathrm{C}$ by doing anything they want in any possible circumstance they find themselves in. There must be restrictions. A pilot can exercise her knowledge how to fly planes in normal circumstances by operating an advanced flight simulator, whereas she cannot exercise her knowledge how to fly planes in normal circumstances by dancing the mambo in a drunken stupor. Although scope of

various ways of doing this: beating it with a chain, kicking it with steel toe boots, throwing heavy objects against it, etc. You count as knowing how to distress furniture if you how to employ one of these ways.

${ }^{8}$ Hawley (2003) and Bengson and Moffett (2011, 192).

${ }^{9}$ Emphasis should be placed on our usual ways of forming beliefs. There are wild ways of using, for example, our perceptual experiences that fails to constitute our perceptual way of knowing. We ordinarily gain perceptual propositional knowledge, roughly, by transitioning from perceptual experiences as of $\mathrm{P}$ to a belief that $\mathrm{P}$. This description leaves much unsaid for there are further mental processes involved in our perceptual way of knowing. For example, we tend to be sensitive to defeating conditions which, upon detection, halt the perceptual belief-forming process. But specifying the belief-forming processes that constitute our ways of knowing in detail is a task for another time. 
this paper does not permit us to consider the various ways one might attempt to specify the intuitive restrictions that exist here, it should be clear from these sorts of examples that such restrictions do exist and our intuitive grip on them is enough for us effectively theorize with.

\section{Refinements}

(T1) cannot be true. For, although exercising know-how is not factive, knowing how to know that $P$ in $C$ is quasi-factive. According to (i.a)-(i.c) one can have such know-how only if there is a way of coming by propositional knowledge of $\mathrm{P}$ in $\mathrm{C}$, and one would succeed in knowing that $\mathrm{P}$ were one to exercise that know-how in $C .{ }^{10}$ Accordingly, one can possess knowledge how to know that $\mathrm{P}$ in $\mathrm{C}$ only if $\mathrm{P}$ is true and knowledgeable when one is in $C$. Because of this, (T1) rules out the possibility of justified false beliefs in $\mathrm{C}$ as well as having justified true beliefs in $\mathrm{C}$ that cannot be known due to epistemic luck (as in gettier cases). But that is implausible...or so says epistemological orthodoxy.

We can make space for such beliefs to be justified by changing (T1)'s circumstantial parameter in the following way. Let ' $\mathrm{C}_{@}$ ' refer to the type of a thinker's actual circumstances and 'the $\mathrm{C}_{P} \mathrm{~s}$ ' refer to the collection of the types of circumstances in which it is possible for $\mathrm{S}$ to know how to know that $\mathrm{P}$ (because conditions (i.a)-(i.c) are satisfiable in each of the $\mathrm{C}_{P} \mathrm{~s}$ ). We can then adjust (T1) to permit justified false beliefs and justified gettier beliefs as follows:

Justification is Knowing How to Know That: Take 2

(T2) S's belief that $\mathrm{P}$ is justified in $\mathrm{C}_{@} \operatorname{IFF}\left(\mathrm{i}^{\prime}\right) \mathrm{S}$ knows how to know that $\mathrm{P}$ in the $\mathrm{C}_{P} \mathrm{~s}$, (ii) S's believing $\mathrm{P}$ is a result of her exercise of that know-how in $\mathrm{C}_{@}$, and (iii) $\mathrm{S}$ is I-related to $\mathrm{C}_{@}$ and the $\mathrm{C}_{P} \mathrm{~S} .{ }^{11}$

So long as (T2) allows $\mathrm{C}_{@}$ to be distinct from each of the $\mathrm{C}_{P} \mathrm{~s}$ it creates the possibility of having justified false beliefs as well as justified gettier beliefs. For even if such beliefs cannot be known in one's actual circumstances, according to (T2) one can yet have a justified belief in them so long as there are other circumstances where they are knowledgable. Thus (T2) easily avoids (T1)'s problem (see section 4.1 for discussion of examples).

However, it is clear that $\mathrm{S}$ cannot have justification to believe $\mathrm{P}$ in any circumstances she find herself in just because it's possible for her to know how to know that $\mathrm{P}$ in some

\footnotetext{
${ }^{10}$ See footnote 6 for discussion of this success condition.

${ }^{11}$ Present talk of "circumstances" typically refers to circumstance types, and the relation "is one of" (below) relates one type to a collection of types. Circumstance tokens are referred to when a thinker is said to be "in" a circumstance type. For example, "S is in C@" means that S's token circumstance is of the type C@.
} 
circumstances. ${ }^{12}$ So we need to specify a suitable relation that holds between $\mathrm{S}, \mathrm{C}_{@}$, and the $\mathrm{C}_{P} \mathrm{~S}$. This is the business of the I-relation. The most plausible specification of the I-relation will be one that appreciates what is common between gettier cases and cases where one is misled so as to have a justified false belief: they are cases where the thinker in question is, in some way or other, unaware of the unfortunate nature of her circumstances. Put differently, in such circumstances $\mathrm{S}$ is in a position where her actual circumstances are in some way "indistinguishable" from circumstances where she would not have been misled and would have had propositional knowledge.

Appreciating these points naturally directs us to the following specifications of the Irelation:

\section{Dogmatism About The I-Relation}

Weak Dogmatism: $\mathrm{S}$ is I-related to $\mathrm{C}_{@}$ and the $\mathrm{C}_{P} \mathrm{~S}$ just in case: $\mathrm{S}$ doesn't know that $\mathrm{C}_{@}$ is not one of the $\mathrm{C}_{P} \mathrm{~s}$.

When inserted into (T2), this amounts to saying that justifiedly believing $\mathrm{P}$ requires that $\mathrm{S}$ doesn't know that she's not in a circumstance where it's possible for her to know that P. ${ }^{13}$ Due to the ease with which one can fail to have knowledge-e.g. defeaters, gettier factors, etc.-requiring an absence of knowledge is too weak a condition to be plausible. If so, here's an alternative specification of the I-relation:

Strong Dogmatism: $\mathrm{S}$ is I-related to $\mathrm{C}_{@}$ and the $\mathrm{C}_{P} \mathrm{~S}$ just in case: $\mathrm{S}$ lacks adequate reason to think that $\mathrm{C}_{@}$ is not one of the $\mathrm{C}_{P} \mathrm{~S} .{ }^{14}$

When inserted into (T2), this amounts to saying that justifiedly believing $\mathrm{P}$ requires that $\mathrm{S}$ lack adequate reason to think she's not in a circumstance where it's possible for her to know that P. The basic idea behind Dogmatist ways of restricting (T2) is that they permit one to have justification in, say, classical skeptical cases (e.g. BIV scenarios) because they are cases where, although one cannot know how to know that P in those circumstances, skeptical circumstances are in a certain sense "indistinguishable" from circumstances in which one does know how to know that $\mathrm{P}$ and, for all one knows, one is in such a case. The same holds in more mundane cases of misleading evidence and gettier cases, for what is characteristic

\footnotetext{
${ }^{12}$ There are further reasons to include an I-relation discussed at the end of this section.

${ }^{13}$ Williamson (2000).

${ }^{14}$ In the knowledge-first spirit it is natural to seek for a knowledge-first account of having reasons for belief. One way of doing this is by taking having a reason to believe that $P$ to be roughly a matter of being in a position to have a justified belief that $P$, where having a justified belief is to be cashed out in terms of one's preferred knowledge-first theory of justification, e.g. $(\mathrm{J}=\mathrm{KH})$ below. This is not problematically circular since familiar recursive techniques can kick-in here.
} 
of those cases is one's inability to discern that one's evidence is misleading or that they've been subject to epistemic luck. ${ }^{15}$

Of course one might think Dogmatist specifications of the I-relation are too weak, maintaining that one must also have some sort of positive reason to think one is in the kind of circumstances where obtaining propositional knowledge is possible. Hence:

\section{Conservatism About The I-Relation}

Weak Conservatism: $\mathrm{S}$ is I-related to $\mathrm{C}_{@}$ and the $\mathrm{C}_{P} \mathrm{~s}$ just in case: $\mathrm{S}$ has adequate reason to think that $\mathrm{C}_{@}$ is one of the $\mathrm{C}_{P} \mathrm{~s}$.

Strong Conservatism: $\mathrm{S}$ is I-related to $\mathrm{C}_{@}$ and the $\mathrm{C}_{P} \mathrm{~s}$ just in case: $\mathrm{S}$ knows that $\mathrm{C}_{@}$ is one of the $\mathrm{C}_{P} \mathrm{~s}$.

Such specifications are more demanding than their Dogmatist counterparts, requiring one to have adequate reason to think/know that one $i s$ in epistemically favorable circumstances with respect to the belief in question. ${ }^{16}$ Perhaps there are less demanding permutations that fall between those outlined above. But in what follows I will defend no particular specification of the I-relation. This is a choice-point for advocates of the knowledge-first approach to justification I'm defending.

So (T2) avoids the problems generated by (T1)'s tight circumstantial parameter. But there is a lingering problem that (T2) faces. For no matter how loose one's circumstantial parameter is, some propositions are beyond knowledge, e.g. the necessarily false. But this conflicts with the common thought that we can have justified beliefs in necessarily false propositions. Frege, arguably, justifiedly believed the Naive Comprehension Axiom.

The solution to this problem is to focus on the fact that one may believe $\mathrm{P}$ as a result of exercising a way of knowing in $C$ despite the fact that $\mathrm{P}$ cannot be known. For even if one cannot know how to know that $P$-because $\mathrm{P}$ is necessarily false-one can still believe $\mathrm{P}$ as the result of an exercise of a way of knowing other propositions. For example, one way of coming by propositional knowledge is believing on the basis of testimony you have strong reason not to doubt. Suppose Frege asserted that the fifth proposition on the board is a logical truth, though it is actually a necessary falsehood. Frege's student might give the assertion some

\footnotetext{
${ }^{15}$ Hawley $(2003)$ and Stanley $(2011,215)$ have claimed that the possession of know-how may be subject to an anti-luck condition. For some resistance see Poston (2009, 744), Cath (2011, section 1), and Carter and Pritchard (forthcoming). But even if the Hawley-Stanley thought is correct, the kind of epistemic luck that compromises one's possession of propositional knowledge on a given occasion doesn't (or at least typically wont) compromise one's possession of (or exercise of) know-how on the same occasion.

${ }^{16}$ For one response to over-intellectualization worries with conservative positions see Silva (2013). Also, it should be noted that Strong Conservatism implies that justification requires that you not only know how to know in the good case but that you also know that you're in the good case. This seems implausibly strong. Thanks are due to an Episteme referee for pointing this out to me.
} 
consideration, see no problem with that particular assertion, and believe the assertion on the basis of Frege's testimony. Although the student has not exercised a way of knowing the fifth proposition (since it cannot be known), she has exercised her knowledge how to acquire propositional knowledge of other propositions on the basis of testimony by forming her belief in the particular way that she did. Similarly for Frege. Frege knew how to acquire propositional knowledge of a certain range of logical and mathematical propositions. The way in which Frege acquired such propositional knowledge was perhaps complex, involving no simple movement from, say, the intuition that $\mathrm{P}$ to belief in P. It likely involved further checks and balances we needn't pause over. The key observation here is that in arriving at his belief in the Naive Comprehension Axiom in, say, the intuition-driven way that he did, Frege exercised his knowledge how to acquire propositional knowledge of other propositions in an intuition-driven way. ${ }^{17}$

Here's a permutation of (T2) that homes in on these facts. Letting 'the $\mathrm{C}_{W} \mathrm{~s}$ ' refer to the collection of the type of circumstances in which $\mathrm{W}$ is a way of gaining propositional knowledge of certain propositions:

Justification is Knowing How to Know That: The (near) Final Take $(\mathrm{J}=\mathrm{KH})$ S's belief that $\mathrm{P}$ is justified in $\mathrm{C}_{@} \operatorname{IFF}(\mathrm{i}$ ") $\mathrm{S}$ knows how to gain propositional knowledge (of certain propositions) in the $\mathrm{C}_{W} \mathrm{~s}$ in some way W, (ii') S's believing $\mathrm{P}$ in $\mathrm{C}_{@}$ results from her exercise of $\mathrm{W}$, and (iii') $\mathrm{S}$ is I-related to $\mathrm{C}_{@}$ and the $\mathrm{C}_{W}$ s.

Condition (i") tells us that S must have a way of acquiring propositional knowledge to have justification. As discussed above, believing on the basis of testimony one has reason to trust (as Frege's student did) and believing on the basis of intuitions (in the way that Frege did) are ways of acquiring propositional knowledge. Other ways will involve forming beliefs on the basis of perceptual experiences, memorial experiences, reasoning under certain conditions, and so forth. Condition (ii') tells us that $\mathrm{S}$ must believe $\mathrm{P}$ as an exercise of some subset of those ways if she's to have justification. $(\mathrm{J}=\mathrm{KH})$ is, save one minor "revision" below, the general account of justification I will be defending on the grounds that it can account for a greater range of intuitive facts about justification than any other competing knowledge-first account of justification.

First, $(\mathrm{J}=\mathrm{KH})$ grounds justification in an uncontroversial fact: we are knowers who have ways of acquiring propositional knowledge. Moreover, this is a fact that is closely linked to

\footnotetext{
${ }^{17}$ Don't put too much stock in my use of the term "intuition". In speaking of Frege forming his belief in an intuition-driven way I just mean to draw attention to the general, non-perceptual, non-introspective, non-testimonial, etc. way in which Frege formed beliefs in logical truths, a way that was often knowledgeyielding.
} 
justification whatever one's view of justification happens to be. For whenever we successfully exercise our knowledge how to acquire propositional knowledge of $\mathrm{P}$ by employing some such way it follows that we not only know that $\mathrm{P}$ but that we also have a justified belief in $\mathrm{P}$. $(\mathrm{J}=\mathrm{KH})$ explains why this is. And even when we unsuccessfully exercise that know-how, and hence fail to acquire propositional knowledge, the result is typically a justified belief. $(\mathrm{J}=\mathrm{KH})$ says this is not merely an accidental correlation between know-how and justification. Rather, this kind of know-how plays a key role in explaining justification.

Second, $(\mathrm{J}=\mathrm{KH})$ vindicates the now-common thought that justification is crucially connected to intellectual virtue. ${ }^{18}$ For knowing how to gain propositional knowledge is such a virtue. Accordingly, $(\mathrm{J}=\mathrm{KH})$ is in keeping with broadly virtue-theoretic approaches to epistemic justification. It differs in that standard virtue theories are developed in the context of abilities rather than know how. I have here preferred a know-how based account for two reasons. First, Hawley (2003) has done a great bit of work elucidating the general structure of know how. Second, it's intuitive to think that, provided know-how and abilities are distinct, know-how is a more likely a place to look to ground propositional knowledge and justification that than abilities absent know-how (more on this in the Kelp discussion below).

Third, $(\mathrm{J}=\mathrm{KH})$ can explain the way in which the dogmatist/conservative debate of almost the last two decades hasn't been just a pointless debate in the theory of justification. ${ }^{19}$ For there is a substantive question as to just which specification of the I-relation is correct. And many of the considerations raised by dogmatists and conservatives of a non-knowledge-first approach to justification can be brought to bear on this question with relative ease.

Finally, although $(\mathrm{J}=\mathrm{KH})$ is not clearly a form of internalism, ${ }^{20}$ it is internalist-friendly insofar as it respects certain core internalist intuitions. For suppose $\mathrm{S}$ exercises her knowledge how to acquire propositional knowledge by believing $\mathrm{P}$ on the basis of her perceptual experience. Notice that being in the sort of conditions needed to acquire perceptual knowledge is not an essential part of S's exercise of that know-how. For just as a pilot can exercise her knowledge how to fly a plane when unwittingly placed in a cleverly constructed flight simulator, a thinker can exercise her knowledge how to acquire propositional knowledge when she's the unwitting victim of an envattment procedure. Ways of acquiring propositional knowledge are constituted by ways of transitioning to belief states. So every exercise of a way of acquiring propositional knowledge in $\mathrm{C}$ is an exercise of a way of transitioning to a belief state. This exercise is constituted by triggering certain belief-forming dispositions and

\footnotetext{
${ }^{18}$ Sosa (2007), Turri (2010), Greco (2010; 2012), and Zagzebski (1996).

${ }^{19}$ Pryor (2000), Silins (2008), Cohen (2002), Wright (2007), Silva (2013), and White (2006).

${ }^{20}$ E.g. it isn't clearly a form of mentalism or access internalism.
} 
capacities which-because it's a way of knowing in C-would yield knowledge if one were in C. But one needn't be in $\mathrm{C}$ for those dispositions and capacities to be triggered. So conditions (i") and (ii') don't appear to carry any strongly externalist conditions in their wake. Thus, if $\mathrm{S}^{*}$ knows how to do the same things as $\mathrm{S}$ does, and $\mathrm{S}^{*}$ exercises that same know-how as $\mathrm{S}$ does in believing $\mathrm{P}$ on the basis of her perceptual experience, it will follow from $(\mathrm{J}=\mathrm{KH})$ that $\mathrm{S}^{*}$ has justification iff $\mathrm{S}$ does-so long as condition (iii') is satisfied for both $\mathrm{S}$ and $\mathrm{S}^{*} .^{21}$ Thus, provided one's preferred specification of condition (iii') doesn't generate any problems, advocates of $(\mathrm{J}=\mathrm{KH})$ can endorse:

(NEG) The extent to which $\mathrm{S}$ is justified at $\mathrm{t}$ in believing that $\mathrm{P}$ is just the same as the extent to which S's recently envatted duplicate is justified at $t$ in believing that $\mathrm{P}^{22}$

It is beyond the scope of this paper to defend (NEG). But as Neta and Pritchard (2007) point out, (NEG) is among the most widely influential internalist intuitions in recent epistemology. Accordingly, $(\mathrm{J}=\mathrm{KH})$ 's compatibility with (NEG) is a significant mark in its favor. ${ }^{23}$

In certain ways, $(\mathrm{J}=\mathrm{KH})$ resembles two recent knowledge-first views of justification. First, according to Lisa Miracchi, a justified belief is, roughly, a belief that is the result of the exercise of some competence to know, where such competences are reliable abilities to know. Accordingly, hers is a thoroughly reliabilist account of justification, making the accommodation of internalist intuitions like (NEG) impossible. And the only apparent way to get her view to accommodate (NEG) is to drop the reliabilist constraint on abilities and to introduce something like the circumstance-relative machinery developed above in the progression from $(\mathrm{T} 1)$ to $(\mathrm{J}=\mathrm{KH})$. Thus, insofar as internalist intuitions are pervasive and well-

\footnotetext{
${ }^{21}$ Strong and Weak Dogmatism are internalist-friendly since they only require the absence of knowledge/adequate reason to think that one's circumstances are unfavorable. Weak Conservatism only requires one to have adequate reason to think one's circumstances favorable, which can also be given an internalistfriendly construal-though it may be more controversial.

${ }^{22}$ The primary difference between you and your recently envatted brain state duplicate lies in the external factors that trigger the dispositions and capacities that constitute the way of knowing you both possess and exercise in response to, say, your apparent perceptual experiences. One might suspect that $(\mathrm{J}=\mathrm{KH})$ is unable to handle internalist intuitions because one thinks the external factors that trigger a way of knowing are relevant to having justification. I doubt internalists will be sympathetic to this kind of worry. Externalists might be, but it strikes me as a choice-point for externalists who, because they're externalists, shouldn't be worried about $(\mathrm{J}=\mathrm{KH})$ 's ability to accommodate (NEG) in the first place.

${ }^{23}$ One place a kind of externalism might poke its head in concerns one's acquisition of know-how in the first place. For example, it might be that knowing how to acquire propositional knowledge in a perceptual way depends on being adequately situated in a certain environment to begin with; or if we're born with such know-how, it may require having ancestors who were so situated. Insofar as this is plausible, advocates of $(\mathrm{J}=\mathrm{KH})$ cannot endorse unrestricted claims that any internal (non-factive) mental state duplicates are justificatory duplicates. Rather, they can at most endorse the view that any internal (non-factive) mental state duplicates who share the same know-how are justificatory duplicates. Even thus restricted, what remains for those who endorse $(\mathrm{J}=\mathrm{KH})$ is a thesis that can pick up many internalist intuitions.
} 
grounded, Miracchi's account faces an objection stemming from (NEG), one that $(\mathrm{J}=\mathrm{KH})$ nimbly dodges. This is not to say that Miracchi is unable to explain away the intuition in terms some other positive epistemic property distinct from justification. Like any other externalist she can appeal to blamelessness or excusability or some other non-justificatory property. ${ }^{24}$ It's just that $(\mathrm{J}=\mathrm{KH})$ can explain $(\mathrm{NEG})$ and therefore we needn't introduce an error theory to explain it away.

The second recent knowledge knowledge-first view of justification is Christoph Kelp's view. According to Kelp: one has a justified belief that $\mathrm{P}$ if and only if one competently believes that P. Here's his account of competent belief:

Justified Belief is Competent Belief $(J=C B)$. One competently believes that $\mathrm{P}$ IFF one's belief that $\mathrm{P}$ is formed by an exercise of an ability to know propositions in range $\mathrm{R}$ and relative to conditions $\mathrm{C}$ such that $\mathrm{P} \in \mathrm{R} .{ }^{25}$

Like Miracchi's preferred account, Kelp prefers an account of justification that is cast in terms of competences to know that $\mathrm{P}$ rather than knowing how to know that $\mathrm{P}$. But unlike Miracchi's view his view is potentially able to accommodate (NEG) due to it's relativization of the relevant competences to circumstances. ${ }^{26}$

So why prefer $(\mathrm{J}=\mathrm{KH})$ to $(\mathrm{J}=\mathrm{CB})$ ? The first reason to prefer $(\mathrm{J}=\mathrm{KH})$ to $(\mathrm{J}=\mathrm{CB})$ is that $(\mathrm{J}=\mathrm{CB})$ lacks anything like an I-relation. $(\mathrm{J}=\mathrm{KH})$ 's inclusion of an I-relation not only locates a legitimate place for the dogmatist/conservative debate in epistemology, but it also protects $(\mathrm{J}=\mathrm{KH})$ against counterexamples that $(\mathrm{J}=\mathrm{CB})$ faces. These counterexamples to $(\mathrm{J}=\mathrm{CB})$ crop up in connection with the fact that one can exercise an ability to (or knowledge how to) know propositions in a certain range of favorable circumstances $C$, while being in circumstances, $\mathrm{C}^{*}$, that one has good reason to think are unfavorable for acquiring propositional knowledge. For example, suppose you knew there were cadres of crazed scientists roaming the land, envatting brains at every turn. Suppose further that you had vivid memories of boffins armed with evattment equipment storming your home and subduing you. Furthermore, suppose that the beginning of the envattment procedure created various visual blips and other discontinuities in your visual field which are persisting. In such circumstances you could know that you were the subject of an envattment procedure and that your perceptual beliefs no longer reliably track reality. Yet, despite your new unfavorable circumstances, you could still exercise your competence to acquire propositional knowledge ${ }^{27}$ in favorable

\footnotetext{
${ }^{24} \mathrm{Cf}$. Littlejohn (forthcoming) and Williamson (forthcoming).

${ }^{25} \mathrm{Kelp}$ (forthcoming, 14-15). And, one has an ability to know propositions in range, $\mathrm{R}$, and relative to conditions, $\mathrm{C}$, IFF one has a way of belief formation, $\mathrm{W}$, such that, for any $\mathrm{p} \in \mathrm{R}$, using $W$ in $C$ disposes one to form knowledgeable beliefs that $\mathrm{p}$.

${ }^{26}$ I say "potentially" because Kelp (forthcoming) doesn't develop this aspect of his view.

27 ...as well as your knowledge how to acquire propositional knowledge...
} 
circumstances by forming perceptual beliefs in response to your visual experiences in the way you normally would. $(\mathrm{J}=\mathrm{CB})$ implies that such post-envattment perceptual beliefs would be justified because they result from an exercise of your ability to acquire propositional knowledge in favorable circumstances. But surely such beliefs would be unjustified. $(\mathrm{J}=\mathrm{KH})$ is protected against any such problematic implication given its inclusion of an I-relation. For such beliefs are formed in the face of one's knowledge of one's own envattment, and hence one's knowledge that one's circumstances are no longer fit for forming perceptual beliefs about one's immediate environment. ${ }^{28}$

A defender of $(\mathrm{J}=\mathrm{CB})$ might object that any way of forming beliefs that doesn't halt the perceptual belief-forming process in response to such evattment information is not really a competence to know. But that is incorrect. For there are two kinds of competences (and kinds of know-how) to be distinguished. First there are the simple, unreflective competences that take no note of factors that indicate that one might be in unfavorable circumstances for the employment of the simple competence. Simple competences are what young children possess, children who have not yet come to realize (nor are they in a position to realize) the many ways in which one can be misled by one's environment. Yet, as with all competences according to Kelp, these simple competences are circumstance relative. So a simple competence to know that $P$ in favorable circumstances remains a competence that one can possess and exercise even if one is not actually in favorable circumstances.

But there is a second, more epistemically advanced competence that we develop over time. It's a competence to selectively employ the simple competence, a competence that is (at least partially) responsive to factors that indicate that one's circumstances are not fit for the employment of the simple competence. The advanced competence does not make the simple competence any less of a competence in favorable circumstances. It just helps us appropriately respond to facts pertaining to whether or not we're actually in such favorable circumstances, i.e. the circumstances relative to which the simple competence is indeed a competence. Without something broadly like an I-relation our ability to monitor our circumstances and appropriately respond to information indicating that we are in circumstances unfit for employing a given competence becomes justificatorily irrelevant. This simply isn’t plausible. A way out of this quandary lies with an I-relation.

$(\mathrm{J}=\mathrm{CB})$ can obviously be augmented so as to include an I-relation, and I would advise advocates of $(\mathrm{J}=\mathrm{CB})$ to do so. Is there any reason to prefer $(\mathrm{J}=\mathrm{KH})$ to an augmented version of $(\mathrm{J}=\mathrm{CB})$ ? To fix ideas, take a view of justification as competent belief that includes an I-relation and employs more of the ideology of $(\mathrm{J}=\mathrm{KH})$ than Kelp's thesis:

\footnotetext{
${ }^{28}$ I suspect the existence of cases like this will motivate one to be at least a Strong Dogmatist since the kind of knowledge failure Weak Dogmatism is concerned with is too easy to come by.
} 


\section{$(\mathrm{J}=\mathrm{CB}+) \mathrm{S}$ 's belief that $\mathrm{P}$ is justified in $\mathrm{C}_{@} \operatorname{IFF}\left(\mathbf{i}^{\prime *}\right) \mathrm{S}$ has a competence} to gain propositional knowledge (of certain propositions) in the $\mathrm{C}_{W} \mathrm{~s}$ in some way W, (ii') S's believing $\mathrm{P}$ in $\mathrm{C}_{@}$ results from her exercise of $\mathrm{W}$, and (iii') $\mathrm{S}$ is I-related to $\mathrm{C}_{@}$ and the $\mathrm{C}_{W} \mathrm{~s}$.

One way of evaluating $(\mathrm{J}=\mathrm{KH})$ vis-a-vis $(\mathrm{J}=\mathrm{CB}+)$ is to see if there are any properties of justification that we would expect a theory of justification to explain, and to see if both $(\mathrm{J}=\mathrm{KH})$ and $(\mathrm{J}=\mathrm{CB}+)$ prove equal to that task. For example, justified belief seems to be a cognitive achievement in at least the sense that a thinker whose belief is justified is creditworthy for believing as she does (more on this in section 4.3). ${ }^{29}$ Do exercises of knowhow as well as exercises of competences constitute a cognitive achievement? Bengson and Moffett (2011) have argued on behalf of intellectualism that behavioral-dispositional states (and hence competences) are unable to explain the fact that there is a constitutive connection between know-how and cognitive achievement. ${ }^{30}$ If they are right, then any competence based approach to justification will be unable to explain the fact that justified belief is a cognitive achievement. This would afford us a strong reason to prefer $(\mathrm{J}=\mathrm{KH})$ to $(\mathrm{J}=\mathrm{CB}+)$ as an explanation of what justifies belief.

But let's assume anti-intellectualists can rally an explanation for know-how's connection to cognitive achievement, and for simplicity let's assume that the version of antiintellectualism at issue reduces knowing how to know that $P$ in $C$ to a competence to know that $P$ in $C .^{31}$ This may appear to be a reason to favor $(\mathrm{J}=\mathrm{CB}+)$ over $(\mathrm{J}=\mathrm{KH})$. But it's not. For if knowing how to know that $P$ in $C$ is reducible to a competence to know that $P$ in $C$, then $(\mathrm{J}=\mathrm{KH})$ will be reducible to $(\mathrm{J}=\mathrm{CB}+)$. In this case, $(\mathrm{J}=\mathrm{KH})$ turns out to be true and able to explain what justifies belief just because $(J=K H)$ is $(J=C B+)$ and because $(\mathrm{J}=\mathrm{CB}+)$ is true and able to explain what justifies belief. Given such a reduction, $(\mathrm{J}=\mathrm{KH})$ and $(\mathrm{J}=\mathrm{CB}+)$ are theses that neither conflict nor compete as explanations of justified belief.

So while $(\mathrm{J}=\mathrm{KH})$ remains a viable explanation of justification for intellectualists who think competences cannot constitute cognitive achievements, $(\mathrm{J}=\mathrm{CB}+)$ does not. But

\footnotetext{
${ }^{29}$ There is a robust sense of "cognitive achievement" that involves one being creditworthy for succeeding in obtaining propositional knowledge. If justification is what results when one pursues propositional knowledge independently of whether or not one actually achieves propositional knowledge, then justified belief will not always be a robust cognitive achievement. This subtlety does not affect the following remarks. For if competences cannot explain one's cognitive achievement in the robust sense then it cannot plausibly explain one's cognitive achievement in the non-robust sense either.

${ }^{30}$ They use this fact about know-how to motivate intellectualism and the rejection of anti-intellectualism.

${ }^{31}$ In support of such a reduction it helps to observe that the following equivalence is hard to refute: $\mathrm{S}$ has a competence (=reliable ability) to know that $\mathrm{P}$ in $\mathrm{C}$ IFF $\mathrm{S}$ knows how to know that $\mathrm{P}$ in $\mathrm{C}$. The difficulty of refuting the right-to-left direction is owed to (i.c) above. The difficulty of refuting the other direction is owed to the fact that propositional knowledge excludes the kinds of luck that usually generate counterexamples to the general thesis that having the ability to $\phi$ entails knowing how to $\phi$.
} 
those anti-intellectualists who reduce the relevant know-how to competences and advocate $(\mathrm{J}=\mathrm{CB}+)$ will not have any reason to reject the explanation of justification that $(\mathrm{J}=\mathrm{KH})$ offers. They'll just take $(\mathrm{J}=\mathrm{CB}+)$ to be a more metaphysically illuminating explanation of justification because it clues us in to the nature of know-how. There are obviously many rabbit trails here, for there are many different ways of being an (anti-)intellectualist. If the number of (anti-)intellectualist analyses of know-how is $n$, then there will be as many ways of endorsing $(\mathrm{J}=\mathrm{KH})$. What I hope to have shown is both that $(\mathrm{J}=\mathrm{CB}+)$ and $(\mathrm{J}=\mathrm{KH})$ are not necessarily in any tension, and that $(\mathrm{J}=\mathrm{KH})$ is something intellectualists and antiintellectualists needn't disagree about despite their differing opinions on the nature of knowhow. ${ }^{3233}$

\section{Collateral Benefits of $(\mathrm{J}=\mathrm{KH})$}

Various knowledge-first views of justification have been proposed in the last decade. $(\mathrm{J}=\mathrm{KH})$ joins their ranks. But what is there to be said in favor of $(\mathrm{J}=\mathrm{KH})$ vis-a-vis alternative knowledge-first accounts of justification? Much and more. My strategy in what follows is to highlight intuitively plausible properties of justification that $(\mathrm{J}=\mathrm{KH})$ is able to accommodate without introducing any kind of error theory. I introduce these properties of $(\mathrm{J}=\mathrm{KH})$ by introducing other knowledge-first views that have had trouble accommodating those features of justification without an error theory.

\subsection{Fallibility and Gettier Cases}

While I've sought to explain justification in terms of a certain kind of practical knowledge, others have sought to identify justification with propositional knowledge itself:

$(\mathrm{J}=\mathrm{K}) \mathrm{S}$ 's belief that $\mathrm{P}$ is justified IFF $\mathrm{S}$ knows that $\mathrm{P} .{ }^{34}$

Here are two core intuitions about justification that $(\mathrm{J}=\mathrm{K})$ cannot accommodate without an error theory. 35

First, justification is fallible. But $(\mathrm{J}=\mathrm{K})$ is inconsistent with the fallibility of justification because propositional knowledge is factive. So $(\mathrm{J}=\mathrm{K})$ cannot permit justified false beliefs.

\footnotetext{
${ }^{32}$ This is not to say that every view of the nature of know-how can be unproblematically plugged into $(\mathrm{J}=\mathrm{KH})$. But it's likely that any view of the nature of know-how that generates oddities in connection with $(\mathrm{J}=\mathrm{KH})$ will generate more general problems that are not at all specific to $(\mathrm{J}=\mathrm{KH})$.

${ }^{33} \mathrm{I}$ 'm grateful to an Episteme referee who helped me consider the relationship between $(\mathrm{J}=\mathrm{KH})$ and (anti-)intellectualism more carefully.

${ }^{34}$ Sutton (2005), Littlejohn (2012, 236-7), and Williamson (2014, 5).

${ }^{35}$ For such error theories see Littlejohn (forthcoming) and Williamson (forthcoming).
} 
But any theory of justification that rules out such beliefs is to that extent implausible, and must appeal to some kind of error theory to explain away these "misleading" appearances. ${ }^{36}$

In contrast, $(\mathrm{J}=\mathrm{KH})$ has no trouble accounting for the fallibility of justification. For example, it's possible to have a justified false belief that it's raining. Now, knowing how to perceptually determine whether it's raining in certain circumstances is a matter of knowing how to respond to one's perceptual experiences in such a way that knowledge of the weather results in those circumstances. But one's perceptual experiences can be unwittingly misleading, and unwittingly using misleading experiences can lead one to exercise one's knowledge how to acquire propositional knowledge even though the end result of that exercise will be a false belief. In such a case, (i') and (ii') will be satisfied. And since the misleading experience is unwitting, any sensible construal of the I-relation will allow for $(\mathrm{J}=\mathrm{KH})$ 's final condition, (iii'), to also be satisfied. So, according to $(\mathrm{J}=\mathrm{KH})$, the exercise of that know-how can yield a justified false belief that it's raining. Just what we want.

Second, there can be unknown, justified true beliefs. Gettier cases are prominent examples of this. But it has been pointed out that $(\mathrm{J}=\mathrm{K})$ implies that there are no gettier cases because it implies that there can be no cases of justification without knowledge. Obviously, this bucks against a history of strong intuitions to the contrary. ${ }^{37}$

But $(\mathrm{J}=\mathrm{KH})$ faces no such problem. For $(\mathrm{J}=\mathrm{KH})$ allows for justified true beliefs that fall short of knowledge. Suppose S sees a white, fluffy sheep-like animal (which is not itself a sheep) on a hill while knowing that the hill is liable to have sheep scattered about it, and on this basis $\mathrm{S}$ forms the belief that a sheep is on the hill. There is nothing about this kind of case that would prevent the right-hand side of $(\mathrm{J}=\mathrm{KH})$ from being satisfied. For S's belief that a sheep is on the hill can be a product of her knowledge how to know that a sheep is on the hill in certain circumstances even if she is not in fact in those circumstances. This assures us that (i") and (ii') can be satisfied in gettier cases. Again, any sensible construal of the I-relation will allow for $(\mathrm{J}=\mathrm{KH})$ 's final condition, (iii'), to also be satisfied in gettier cases. For gettier cases are cases where one has no reason to think any funny business is going on. So, unlike $(\mathrm{J}=\mathrm{K}),(\mathrm{J}=\mathrm{KH})$ can allow for unknown, justified true beliefs.

\subsection{Inferential Justification and Williamsonian Counterexamples}

Here is Alexander Bird's (2007) knowledge-first account of justification:

(JuJu) If in world $w_{1} \mathrm{~S}$ has mental states $\mathrm{M}$ and then forms a judgment, that judgement is justified IFF there is some world $w_{2}$ where, with the same mental

\footnotetext{
${ }^{36}$ Ichikawa (2014) and McGlynn (2014) develop this point against $(\mathrm{J}=\mathrm{K})$.

${ }^{37}$ Ichikawa (2014), Bird (2007), and Comesana and Kantin (2010).
} 
states M, S forms a corresponding judgement and that judgement yields knowledge.

(JuJu) counts as a knowledge-first theory of justification because it explains one's justification in terms of the knowledge of one's mental state duplicates. And it can do a good deal better than $(\mathrm{J}=\mathrm{K})$ when it comes to accounting for justification's intuitive characteristics, including its internalist character. Despite this, various problems have been pointed out concerning $(\mathrm{JuJu})$, and I'll concentrate on the two problems one might be tempted to extend to $(\mathrm{J}=\mathrm{KH}){ }^{38}$

First, a plausible account of justification will not only allow one to have justified false beliefs, but will allow one to obtain justified false beliefs from justified false beliefs. For example, suppose S knew that:

(a) Hesperus is Venus.

But, due to some misleading evidence, $\mathrm{S}$ had the justified false belief that:

(b) Hesperus is not Phosphorus.

Putting these two together $\mathrm{S}$ could infer that:

(c) Phosphorus is not Venus.

As Ichikawa (2014, 191-192) observes, S could justifiedly believe (c) on this inferential basis. But according to (JuJu) S can justifiably believe (c) on the basis of an inference from (a) and (b) only if it's possible for a mental state duplicate of S's to know (c) on this basis. Content externalism, however, precludes such a possibility. For content externalism implies any mental state duplicate of S's who believes (c) on the basis of (a) and (b) will be a thinker for whom the terms 'Phosphorus' and 'Venus' refer to the very same astral body, thus making knowledge of (c) on the basis of (a) and (b) impossible. Because of this, (JuJu) implies that you cannot have justification to believe (c) on this inferential basis-something many epistemologists will find implausible.

But $(\mathrm{J}=\mathrm{KH})$ encounters no problems here. For according to $(\mathrm{J}=\mathrm{KH}), \mathrm{S}$ can justifiedly believe (c) on the basis of an inference from (a) and (b) so long as S's believing (c) on that basis results from an exercise of her knowledge how to gain propositional knowledge in some way $\mathrm{W}$ (and the other conditions of $(\mathrm{J}=\mathrm{KH})$ are satisfied). This, of course, raises the question: what way of knowing did S exercise in arriving at her belief in (c)? It's clearly an inferential way of knowing. Specifying the details of what an inferential ways of knowing

\footnotetext{
${ }^{38}$ For additional objections to (JuJu) see McGlynn (2012; 2014) and Ichikawa (2014).
} 
involves falls outside the scope of this paper; but it is clear that we do come by propositional knowledge in inferential ways, and that is enough for present purposes. The important point is that, however we characterize our inferential ways of acquiring propositional knowledge, we are able to fallibly exercise those ways. That is, we are able to exercise our inferential ways of knowing even the product of that exercise involves false beliefs. ${ }^{39}$ This, together with $(\mathrm{J}=\mathrm{KH})$, will permit cases like that above where one has a justified inferential belief in (c) even though (c) is unknowable. Thus-just as we saw above in the case of justified beliefs in necessary falsehoods-one can have a justified belief in (c) on the basis of (a) and (b) even if (c) cannot be known or if S comes to believe (c) on the basis of false premises. This is just what we want, and just what (JuJu) cannot deliver.

Second, (JuJu) fails to survive the Williamsonian counterexamples to internalism. Williamson's counterexamples, as McGlynn (2014, 44ff) notes, were not intended to undermine (JuJu) but they do so anyway. Here's one example of the kind of case (JuJu) has difficulty with:

Suppose that it looks and sounds to me as though I see and hear a barking dog; I believe that a dog is barking on the basis of the argument 'That dog is barking; therefore, a dog is barking'. Unfortunately, I am the victim of an illusion, my demonstrative fails to refer, my premise sentence thereby fails to express a proposition, and my lack of a corresponding singular belief is a feature of my mental state, according to the content externalist. If I rationally believe that a dog is barking, then by $[\mathrm{JuJu}]$ someone could be in exactly the same mental state as I actually am and know that a dog is barking. But that person, too, would lack a singular belief to serve as the premise of the inference, and would therefore not know that a dog is barking. ${ }^{40}$

McGlynn $(2014,44)$ draws our attention to the fact that a "natural verdict is that one's belief that a dog is barking is rational or justified" despite the fact that one cannot know this while having the same mental states. For any (non-factive) mental state duplicate will be one for whom the sentence 'That dog is barking' cannot be true, and hence cannot be known either. So we have a counterexample to (JuJu).

\footnotetext{
${ }^{39}$ For example, suppose you have beliefs in P1-Pn that don't amount to propositional knowledge (say because P1 is false). Despite this, suppose you've got great reason to think P1-Pn are true, no reason to think P1-Pn are false, and no reason to think that your evidence for P1-Pn is misleading, and no reason to think that you're subject to some other kind of knowledge-compromising deception. So you're in a pretty good epistemic position with respect to P1-Pn. Now suppose you also realize that Q is entailed by P1-Pn and so you proceed to believe $\mathrm{Q}$ via a competent deduction from $\mathrm{P} 1-\mathrm{Pn}$, and at no point while performing your competent deduction is your epistemic position with regard to P1-Pn compromised. Here you've exercised an inferential way of knowing that we're all quite familiar with. You've just run afoul of some bad luck that prevented you from gaining propositional knowledge.

${ }^{40}$ Williamson $(2000,57-58)$.
} 
Does this double as a counterexample to $(\mathrm{J}=\mathrm{KH})$ ? Not obviously. For $(\mathrm{J}=\mathrm{KH})$ is a thesis about when beliefs with propositional content are justified. Given that, the Williamsonian counterexample leaves $(\mathrm{J}=\mathrm{KH})$ untouched. But even so, it does no good to defend $(\mathrm{J}=\mathrm{KH})$ on grounds of its lack of scope. For, as McGlynn observes, even beliefs that fail to have propositional content can be justified, and a theory of justification should say just when such contentless beliefs are justified.

We can generalize $(\mathrm{J}=\mathrm{KH})$ in such a way as to be neutral on the issue of propositional content:

Justification is Knowing How to Know That: The Final Take $\left(\mathrm{J}=\mathrm{KH}^{*}\right)$ S's belief is justified in $\mathrm{C}_{@} \mathrm{IFF}(\mathrm{i}$ ') S knows how to gain propositional knowledge (of certain propositions) in the $\mathrm{C}_{W}$ s in some way W, (ii") S's belief in $\mathrm{C}_{@}$ results from her exercise of $\mathrm{W}$, and (iii') $\mathrm{S}$ is I-related to $\mathrm{C}_{@}$ and the $\mathrm{C}_{W} \mathrm{~s}$.

As to Williamson's case, there is no reason to think that lack of content prevents one from exercising the very same way of knowing that one would have exercised if one's demonstrative had gained purchase on the world. Thus, $\left(\mathrm{J}=\mathrm{KH}^{*}\right)$ implies that contentless beliefs can be justified, which is just what we want and just what (JuJu) cannot deliver.

\subsection{Credit and Basing}

Since (JuJu)'s problems stem from its insistence on sameness of mental states a natural correction is to abandon that emphasis and focus on what a thinker and, say, her duplicate on Twin Earth can have in common. This is just what Ichikawa $(2014,189)$ attempts to do:

Justification is Potential Knowledge

(JPK) S's belief is justified IFF S has a possible counterpart, alike to $\mathrm{S}$ in all relevant intrinsic respects, whose corresponding belief is knowledge.

The target intrinsic respects are limited to the non-intentional properties that $\mathrm{S}$ and her Twin Earth duplicate can share. But they are not intended to include all such properties. Ichikawa wants to maintain that if, say, S unwittingly lost her body in an envattment procedure, she could still have justification to believe that she has a body even though the only counterparts of hers who could know this are ones who have a body. So the target intrinsic respects are to be further restricted to what $\mathrm{S}$ and her envatted counterpart could share. In the end, this seems to amount to sameness of brain states or something close to that. This aspect of (JPK) goes a long way towards making it internalist-friendly and also helps (JPK) avoid the difficulties facing $(\mathrm{JuJu})$ and $(\mathrm{J}=\mathrm{K}) .{ }^{41}$ Nevertheless, (JPK) has problems of its own.

\footnotetext{
${ }^{41}$ Ichikawa (2014, 189ff).
} 
The first problem with (JPK) involves the following thesis:

(Credit) If $\mathrm{S}$ has a justified belief in $\mathrm{P}$, then $\mathrm{S}$ is creditworthy ( $\approx$ praiseworthy, and hence blameless) in believing $\mathrm{P}^{42}$

For, as (Credit) indicates, justifiedly believing is of credit to the believer, and intuitively one is creditworthy because one is justified. But (JPK) seems forced to explain a thinker's creditworthiness in terms of facts about a believer's intrinsic counterparts since it's one's counterparts that explain one's doxastic justification. But this seems odd: why should a merely possible, distinct individual make me creditworthy for believing as I actually do?

Ichikawa (2014, 192-193) recognizes this problem. As an initial response, Ichikawa argues that (JPK) could be gently revised in terms of transworld identity so that the only counterparts who mattered are those with whom I would be identical. But this does not address the core concern. For not only am $I$ not creditworthy for the knowledge states of other possible individuals, I am not creditworthy for being in a knowledge state I am not actually in. Indeed insofar as it's plausible to maintain that one's having doxastic justification should help explain why a thinker is creditworthy, (JPK) just seems to locate the source of an agent's creditworthiness in the wrong place. Transworld identity there may be. But there is no transworld credit.

Ichikawa's $(2014,193)$ second response seeks to deflect this last concern:

...if I satisfy the conditions of (JPK), and so have a possible counterpart of the relevant sort who has knowledge, it is to a significant degree in virtue of my own (intrinsic) features that this is so.

The idea seems to be that, even if doxastic justification entails creditworthiness, we needn't always ground the credit a believer deserves in the very same factors that ground the believer's justification.

But here's the hitch. Doxastic justification has a basing requirement, ${ }^{43}$ and this makes doxastic justification partly a historical matter. ${ }^{44}$ And epistemic credit and blame also seem

\footnotetext{
42Zagzebski (1996, 300-303) and Ichikawa $(2014,187)$.
}

43 That is,

(Basis) S has a justified belief in $\mathrm{P}$ only if $\mathrm{S}$ has based her belief in $\mathrm{P}$ on epistemically appropriate grounds.

This thesis should perhaps be restricted in light of some plausible cases of justified beliefs that have no basis (see Turri's (2010) discussion of cogito beliefs). But even so, there is a wide range of beliefs (e.g. perceptual and inferential beliefs) where this constraint seems correct. Although Ichikawa does not discuss the basing requirement in his defense of (JPK) he does appear to endorse the view elsewhere. See Ichikawa and Steup (2012, section 1.3.2).

${ }^{44}$ Even internalists are happy to grant this. Cf. Feldman (2014). 
to depend on historical factors too. Thus, Ichikawa's defense of (JPK) is susceptible to cases like the following:

Bad Past: At t S comes to believe that there is a ceiling overhead. S believes this because she just took a pill which she knew would induce random changes in her intrinsic states. In advance of taking the pill, $\mathrm{S}$ knew it would very likely cause her to have many false perceptual beliefs. But as it happens, the pill induced a total re-organization of her intrinsic states such that at $\mathrm{t} S$ has a counterpart who knows a ceiling is overhead.

(JPK) implies that S has a doxastically justified belief in Bad Past because she happens to have a knowledgeable counterpart. So, due to (Credit) and the basing requirement on doxastic justification, (JPK) entails that $\mathrm{S}$ has satisfied the basing relation, $\mathrm{S}$ is creditworthy. But this seems all wrong. For at $\mathrm{t}$ in Bad Past $\mathrm{S}$ hasn't based her belief on appropriate reasons, ${ }^{45}$ and she is not creditworthy, and she is, moreover, positively blameworthy for believing as she does. ${ }^{46}$ For an advocate of (JPK) to resist this they would have to reject (Credit) and the basing requirement on doxastic justification, or else modify (JPK) so that it has the right implications in cases like Bad Past. ${ }^{47}$ Even if this is done in a non-ad hoc manner, (JPK) will run up against a further comparative difficulty. For the knowledge-first virtue epistemology advocated here is one can that easily deal with cases like Bad Past while providing an intuitive explanation for justification's connection to credit and blamelessness.

\footnotetext{
45 (JPK)'s problem with (Basis)-see footnote 43-is that S's belief in Bad Past was immediately caused by the pill. Although it is widely supposed among epistemologists that the basing relation is a causal relation (or involves a causal element disjunctively), for the counterexample to work it is not necessary that the basing relation be a causal relation. All that's necessary for the counterexample is that it be possible for two intrinsic duplicates to differ in whether or not the basing relation obtains with respect to some shared belief. Most theories of the basing relation allow for this. See Korcz (2010) and Turri (2011).

${ }^{46}$ Some internalists might argue that S's belief is justified; but these will not be virtue epistemologists. Moreover, they will encounter difficulty with (Credit) insofar as S is intuitively blameworthy (and hence not creditworthy) for holding her belief despite the re-organization of her intrinsic states.

${ }^{47}$ Ichikawa $(2014,200)$ suggests a revision to (JPK) available for those worried about one's of Goldman's objections to internalism. The move is to revise (JPK) so that $\mathrm{S}$ has a justified belief in $\mathrm{P}$ only if $\mathrm{S}$ has an internal counterpart who knows $\mathrm{P}$ and the past intrinsic states of $S$ and her counterpart's match. This would, I think, save such a revised version of (JPK) from Bad Basis for S and her counterpart do not plausibly overlap in the history of their mental states. S, after all, behaves in a consciously reckless manner in electing to take the pill.

But even this revised version of (JPK) will fall to a revised version of Bad Basis. Just take a case where, although S does not behave in a consciously reckless manner, $\mathrm{S}$ does unwittingly fail to base her belief on an appropriate reason. (This may be due to a pill covertly slipped into a meal, the covert work of an evil demon, etc.) This is possible because the basing relation is a relation that can fail to obtain without affecting the intrinsic states of a thinker, and because the basing relation is not essentially an intrinsic state on any plausible account of the basing relation. Thus, $\mathrm{S}$ can fail to satisfy the basing requirement in believing $\mathrm{P}$ even though the intrinsic states over the course of S's life do match those of her knowledgable counterpart's. So long as the basing relation is necessary for justified belief, (JPK) will be sensitive to this kind of objection. Thanks are owed to an Episteme referee for having me consider this issue.
} 
According to $\left(\mathrm{J}=\mathrm{KH}^{*}\right)$, in order for $\mathrm{S}$ to have a justified belief her belief must result from an exercise of her know-how. And it's obvious that S's know-how played no role in producing her belief in Bad Past. Thus, according to $\left(\mathrm{J}=\mathrm{KH}^{*}\right)$, even if two thinkers share the same intrinsic states at t, it's not guaranteed that their mental states will enjoy the same epistemic statuses at t. For this reason, $\left(\mathrm{J}=\mathrm{KH}^{*}\right)$ is both consistent with and can help explain the intuition that in Bad Past S lacks doxastic justification, creditworthiness, and blamelessness. Accordingly, (Credit) and the basing requirement on doxastic justification don't threaten $\left(\mathrm{J}=\mathrm{KH}^{*}\right)$. Moreover, $\left(\mathrm{J}=\mathrm{KH}^{*}\right)$ can be used to help explain why there is a tight connection between doxastic justification and creditworthiness. For the very conditions that need to be satisfied for a thinker to have doxastic justification seem sufficient for creditworthiness and blamelessness. For if, as knowledge-firsters maintain, propositional knowledge is the aim of belief and one's belief stems from one's exercise of one's knowledge how to acquire propositional knowledge, then not only is one intuitively blameless when one's belief is the result of an exercise of one's knowledge how to acquire propositional knowledge, one also appears creditworthy because their believing as they do is a result of their exercise of their knowledge how to achieve that aim.

\section{Conclusion}

Having seen the counterexamples that challenge other knowledge-first accounts of justification, $\left(\mathrm{J}=\mathrm{KH}^{*}\right)$ can be agued to be extensionally adequate, being able to explain our judgements about when agents have justified beliefs.

Let's conclude by summarizing the other features of justification that $\left(\mathrm{J}=\mathrm{KH}^{*}\right)$ is able to accommodate:

1. $\left(\mathrm{J}=\mathrm{KH}^{*}\right)$ can explain the close connection between justification and our knowledge how to acquire propositional knowledge.

2. $\left(\mathrm{J}=\mathrm{KH}^{*}\right)$ can explain the fact that justification is, in part, the exercise of cognitive virtue.

3. $\left(\mathrm{J}=\mathrm{KH}^{*}\right)$ can explain the way in which the dogmatist/conservative debate has been a relevant debate in the theory of justification.

4. $\left(\mathrm{J}=\mathrm{KH}^{*}\right)$ is internalist-friendly, accommodating certain core internalist intuitions.

5. $\left(\mathrm{J}=\mathrm{KH}^{*}\right)$ can explain the fallibility of justification. 
6. $\left(\mathrm{J}=\mathrm{KH}^{*}\right)$ can explain the existence of unknown, justified true beliefs (e.g. gettier cases).

7. $\left(\mathrm{J}=\mathrm{KH}^{*}\right)$ can explain how justified beliefs can be obtained inferentially from justified false beliefs.

8. $\left(\mathrm{J}=\mathrm{KH}^{*}\right)$ survives the Williamsonian counterexamples to internalism.

9. $\left(\mathrm{J}=\mathrm{KH}^{*}\right)$ can explain how doxastic justification depends on aspects of the causal history of one's belief.

10. $\left(\mathrm{J}=\mathrm{KH}^{*}\right)$ can help explain why having a justified belief ensures that a believer is both blameless and creditworthy for believing as she does.

11. $\left(\mathrm{J}=\mathrm{KH}^{*}\right)$ is extensionally adequate.

No other knowledge-first theory of justification can accommodate the very same characteristics of justification while not encountering other difficulties. ${ }^{48}$ This is a very good reason to prefer $\left(\mathrm{J}=\mathrm{KH}^{*}\right)$ to existing knowledge-first accounts of justification. One upshot of these many explanatory virtues of $\left(\mathrm{J}=\mathrm{KH}^{*}\right)$ is that they lend support to the knowledge-first program. For it shows that the knowledge-first program doesn't demand a starkly revisionary, non-internalist conception of epistemic justification. Rather, $\left(\mathrm{J}=\mathrm{KH}^{*}\right)$ allows the knowledgefirster to take the amicable stance that much of the 20th and early 21st century work on epistemic justification has proceeded on many accurate assumptions about justification. This should go a long way towards assuaging the concerns of those reluctant to put knowledge first.

\section{References}

Alston, W. 1989. Epistemic Justification, Ithaca: Cornell University Press.

Bengson, J. and Moffett, M. 2011. "Non-propositional intellectualism," in Knowing How: Essays on Knowledge, Mind and Action, Bengson, J., Moffett, M. (eds), Oxford University Press.

Bird, Alexander. 2007. "Justified Judging," Philosophy and Phenomenological Research 74: 81-110.

\footnotetext{
${ }^{48}$ There is one further knowledge-first approach to justification I omit discussion of. It is Reynold's (2013) view of justification as the appearance of knowledge. For the problems besetting his view see McGlynn (2014).
} 
Boghossian, P. 2008. Content and Justification. Oxford: Oxford University Press.

Carter, J. A., and Pritchard, D. Forthcoming. "Knowledge-How and Epistemic Luck," Nous.

Cath, Y. 2011. "Knowing How Without Knowing That," Knowing How: Essays on Knowledge, Mind and Action, (eds.) J. Bengson \& M. Moffett, 113-35, Oxford University Press, Oxford.

Cohen, S. 2002. "Basic Knowledge and the Problem of Easy Knowledge," Philosophy and Phenomenological Research, 65: 309-329.

Comesana, J. and Kantin, H. 2010. "Is Evidence Knowledge?" Philosophy and Phenomenological Research 89: 447-455.

Feldman, R. 2014. "Justification is Internal," in Matthias Steup, John Turri, and Ernest Sosa (eds), Contemporary Debates in Epistemology (Second Edition). Oxford: Wiley-Blackwell.

Feldman, R. and E. Conee. 1985. Evidentialism, Philosophical Studies 48: 15-34. Goldman, A. 1988. "Strong and Weak Justification," Philosophical Perspectives 2: $51-69$.

Greco, J. 2010. Achieving Knowledge: A Virtue-Theoretic Account of Epistemic Normativity. Cambridge: Cambridge University Press.

Greco, J. 2012. "A (Different) Virtue Epistemology," Philosophy and Phenomenological Research 85: 1-26.

Hawley, K. "Success and Knowledge-How," American Philosophical Quarterly 40: 19-3.

Ichikawa, J. 2014. "Justification is Potential Knowledge," Canadian Journal of Philosophy 44: 184-206.

Ichikawa, J. and Steup, M. 2012. "The Analysis of Knowledge," Stanford Encyclopedia of Philosophy.

Kelp, C. Forthcoming. "Knowledge First Virtue Epistemology," Carter, A., Gordon, E. and Jarvis, B. eds. Knowledge First: Approaches in Epistemology and Mind. Oxford University Press.

Korcz, K. 2010. "The Epistemic Basing Relation," Stanford Encyclopedia of Philosophy. 
Littlejohn, C. 2012. Justification and the Truth-Connection, Cambridge: Cambridge University Press.

Littlejohn, C. Forthcoming. "Plea for Epistemic Excuses," in Fabian Dorsch Julien Dutant (ed.), The New Evil Demon Problem. Oxford University Press.

Lord, E. and Maguire, B. Forthcoming. "An Opinionated Guide to the Weight of Reasons."

McGlynn, A. 2014. Knowledge First? Palgrave MacMillan.

Millar, A. 2008. "Perceptual-recognitional abilities and perceptual knowledge," in A. Haddock \& F. Macpherson (Eds.), Disjunctivism: Perception, Action, Knowledge. Oxford: Oxford University Press.

Miracchi, L. 2015. "Competence to Know," Philosophical Studies 172: 29-56.

Neta, R. and D. Pritchard. 2007. "McDowell and the New Evil Genius," Philosophy and Phenomenological Research, 74: 381-396.

Poston, T. 2009. "Know-How to be Gettiered?" Philosophy and Phenomenological Research 79: 743-7.

Pritchard, D., A. Millar, and A. Haddock. 2010. The Nature and Value of Knowledge, Oxford: Oxford University Press.

Pryor, J. 2000. "The Skeptic and the Dogmatist," Noûs 34:517-549.

Pryor, J. 2001. "Highlights in Recent Epistemology," The British Journal for the Philosophy of Science 52: 95-124.

Reynolds, S. 2013. "Justification as the Appearance of Knowledge," Philosophical Studies 163: 367-383.

Silins, N. 2008. "Basic Justification and the Moorean Response to the Skeptic," in Oxford Studies in Epistemology Volume 2.

Silva, P. 2013. "How To Be Conservative: A Partial Defense of Epistemic Conservatism," Australasian Journal of Philosophy 91: 501-514.

Sosa, E. 2007. A Virtue Epistemology: Apt belief and reflective knowledge (Vol. 1), Oxford: Oxford University Press.

Stanley, J. 2011. Know How, Oxford University Press, Oxford.

Turri, J. 2010. "On the Relationship Between Propositional and Doxastic Justification," Philosophy and Phenomenological Research 80: 312-326.

Turri, J. 2011. "Believing for a Reason," Erkenntnis 74: 383-397. 
Wedgwood, R. 2002. "Internalism Explained," Philosophy and Phenomenological Research 65: 349-369.

White, R. 2006. "Problems for Dogmatism. Philosophical Studies," 131:525-557. Williamson, T. 2000. Knowledge and its Limits. Oxford: Oxford University Press.

Williamson, T. 2014. "Knowledge First" in Matthias Steup, John Turri, and Ernest Sosa (eds), Contemporary Debates in Epistemology (Second Edition). Oxford: Wiley-Blackwell.

Williamson, T. Forthcoming. "Justifications, Excuses, and Sceptical Scenarios," in Julien Dutant and Fabian Dorsch, eds., The New Evil Demon, Oxford: Oxford University Press.

Wright, C. 2004. "Warrant for Nothing (and Foundations for Free)?" Aristotelian Society Supplementary Volume 78:167-212.

Zagzebski, L. 1996. Virtues of the Mind: An Inquiry Into theNature of Virtue and the Ethical Foundations of Knowledge. Cambridge, MA: Cambridge University Press. 